\title{
Políticas de governança ambiental urbana na arena eleitoral: o caso do Rio de Janeiro nas eleições municipais de 2016
}

\section{Urban environmental governance policies in the electoral arena: the case of Rio de Janeiro in the municipal elections of 2016}

Antonio Teixeira de Barros - Doutor em Sociologia pela Universidade de Brasília (UnB). Docente e pesquisador do Programa de Mestrado em Ciência Política do Centro de Formação da Câmara dos Deputados (CEFOR). E-mail: antonibarros@gmail.com

\section{Resumo}

$\mathrm{O}$ artigo analisa como os 11 candidatos à eleição para a prefeitura do Rio de Janeiro em 2016 incorporaram temas ambientais em seus programas de governo, especialmente propostas de governança ambiental urbana. O levantamento foi realizado no período de setembro a outubro de 2016, durante a campanha eleitoral. A metodologia consiste na análise dos referidos programas. De forma complementar, foram realizadas entrevistas com integrantes das equipes que gerenciaram a campanha eleitoral dos candidatos, a fim de colher subsídios para incrementar a análise qualitativa. As principais conclusões indicam que, dos 11 candidatos, oito apresentaram propostas de governança ambiental para a cidade do Rio de Janeiro. Os programas mais elaborados são de Alessandro Molon, Jandira Feghali e Marcelo Freixo. Isso se deve a três fatores: engajamento pessoal desses candidatos na construção das propostas ambientais, envolvimento com os movimentos e entidades ecológicas e a colaboração de especialistas em políticas públicas e governança ambiental.

\section{Palavras-chave}

Meio ambiente e política. Política municipal e ambiente. Eleições e ambiente. Governança ambiental. Rio de Janeiro.

\begin{abstract}
This article analyzes how the 11 mayoral candidates in the 2016 elections in Rio de Janeiro included environmental issues in their government platforms, especially proposals for urban environmental governance. The survey was conducted from September to October 2016, during the electoral campaign. The methodology consisted of content analysis of platforms. In a complementary way, we interviewed members of the teams that managed the electoral campaign of the candidates, in order to obtain elements to deepen the qualitative analysis. The main conclusions indicate that eight among the eleven candidates submitted environmental governance proposals for the city of Rio de Janeiro. The most elaborate platforms were those of Alessandro Molon, Jandira Feghali and Marcelo Freixo. This was due to three factors: personal engagement of these candidates in the construction of environmental proposals; their involvement with ecological movements and entities; and the collaboration of experts in public policies and environmental governance.
\end{abstract}

\section{Keywords}

Environment and politics. Municipal policy and environment. Elections and environment. Environmental governance. Rio de Janeiro 


\section{INTRODUÇÃO}

O objetivo deste artigo é analisar como os candidatos à prefeitura da cidade do Rio de Janeiro, em 2016, abordaram os temas ambientais no âmbito local. A análise é guiada pelas seguintes questões: Como se deu a incorporação de temas ambientais no programa dos candidatos à prefeitura do Rio, em 2016? Como as temáticas ambientais foram articuladas nos programas dos candidatos? Em que consistem as propostas políticas apresentadas? Qual(is) a(s) noção(ões) de sustentabilidade que orienta(m) o discurso dos candidatos?

A principal hipótese que orienta a pesquisa é que o período eleitoral é relevante e profícuo para ser analisado, por duas razões. A primeira é que se trata do momento em que, ao lançarem suas candidaturas, os partidos usam variadas estratégias para reforçar seu papel na mediação política e seu poder de palavra. Nesse contexto, a hipótese é que a formulação de propostas de governança ambiental tornou-se relevante no contexto das estratégias discursivas dos candidatos, em função da importância que as questões ambientais adquiriram no contexto recente. A segunda razão é que durante o cenário eleitoral as estratégias de publicidade política adquirem maior visibilidade perante o eleitorado (BARROS, 2015a, 2015b, 2017a, 2017b, 2018).

É oportuno ressaltar que o debate político sobre ambiente adquiriu projeção com a intensa midiatização a partir da Cúpula da Terra (Rio 92). Na época a cidade do Rio projetou-se internacionalmente como cenário do debate ambiental. Com a Olimpíada de 2016, novamente os problemas ambientais da cidade adquiriram visibilidade internacional, a exemplo da poluição da Lagoa Rodrigues de Freitas e da Baía de Guanabara.

Com uma população de 11,8 milhões de habitantes, a cidade do Rio é a segunda maior metrópole do Brasil, depois de São Paulo, e a sexta da América Latina. A cidade também é considerada um importante destino turístico internacional no Brasil e na América Latina. Além da paisagem natural internacionalmente reconhecida, a cidade conta ainda com parques e unidades de conservação, como o Parque Nacional da Tijuca - considerado Patrimônio Ambiental e Reserva da Biosfera pela UNESCO -, o Parque Estadual da Pedra Branca, o Complexo da Quinta da Boa Vista, o Jardim Botânico, o Jardim Zoológico do Rio e o Passeio Público. Apesar disso, o Rio é considerado uma cidade complexa do ponto de vista da formulação e execução das políticas urbanas, especialmente no caso das políticas ambientais, avaliadas como periféricas no âmbito mais amplo das demais políticas setoriais (MARQUES, 2000). 
Governança ambiental é entendida aqui como a ação governamental voltada para o controle do uso dos recursos naturais (CÂMARA, 2013). Isso implica considerar aspectos como o planejamento ambiental, o conjunto de regras, normas e processos que orientam a ação governamental na esfera de políticas ou ações ligadas às relações da sociedade com o meio ambiente natural. Em suma, a governança ambiental, no caso dos espaços urbanos, é composta pelo conjunto de arranjos institucionais, especialmente aqueles que orientam as políticas públicas voltadas para a proteção/recuperação dos recursos naturais, bem como o desenvolvimento de tecnologias e inovações para amenizar impactos ambientais, reduzir riscos e prevenir desastres e degradação ambiental (CHAFFIN et al., 2016; BROTO, 2017).

O estudo utiliza-se de análise documental, tendo como base o programa de governo dos candidatos, com o objetivo de mapear de que forma as temáticas ambientais foram incorporadas pelos programas de governo dos referidos candidatos. O levantamento documental foi realizado no período de setembro a outubro de 2016, durante a campanha eleitoral. Os documentos foram submetidos à técnica de análise de conteúdo (AC), nos termos de Bardin (2009). Para tanto recorremos a dois instrumentos da AC: análise categorial e análise de avaliação. A primeira consiste em formular categorias com base nos temas predominantes nos documentos, enquanto a segunda consiste no exame de enunciados opinativos, ou seja, o enquadramento analítico. Para a primeira foi utilizado o software Atlas. Ti, uma ferramenta para análise de conteúdo categorial ou temática, que permite a identificação dos temas principais de textos e documentos escritos (KLÜBER, 2014). O uso do software contribuiu para a primeira parte da análise dos dados (ver quadros 1 a 3). A segunda resultou da leitura e avaliação dos programas dos 11 candidatos, conforme consta na segunda parte da análise.

Para aprofundamento da análise qualitativa foram realizadas entrevistas por telefone com agentes das equipes de marketing das campanhas dos 11 candidatos, no final de novembro de 2016, após a conclusão do levantamento documental. Foram 11 entrevistas, ou seja, sendo um da equipe de cada candidato ${ }^{1}$. As entrevistas foram do tipo semiestruturada, ou seja, com um roteiro previamente definido, mas com possibilidade de inclusão de novas questões de acordo com a dinâmica do diálogo com os entrevistados. Assim, cada entrevista tomou um rumo próprio no decorrer da conversa, sem se prender ao roteiro. O objetivo da entrevista foi obter mais subsídios discursivos dos informantes para o aprofundamento da análise dos dados. Essa estratégia é apontada por Alves e Silva (1992, p. 63) como uma forma de se obter dados "dentro de um contexto",

\footnotetext{
Uma condição da maioria dos entrevistados foi a garantia de anonimato.
} 
o que foi muito útil no caso em estudo, pois foram dados subjetivos relacionados ao contexto da campanha eleitoral dos candidatos.

Antes da apresentação e análise dos dados discutimos alguns aspectos teóricos sobre as relações entre cidade e meio ambiente, além da inserção do debate ambiental verde nas arenas políticas.

\section{CIDADE, POLÍTICA E MEIO AMBIENTE}

As dinâmicas de urbanização produzem ambientes segregados, com elevados impactos na qualidade de vida população (DUNLAP; BRULLE, 2015; IRAZÁBAL, 2017). Cabe ressaltar que a própria cidade é considerada como um tipo de meio ambiente (LYNCH, 1972) e como um bem ambiental (MARQUES, 2014). Trata-se de uma visão ancorada na representação da cidade como "espaço da qualidade de vida" (ACSELRAD, 1999, p. 84). Por outro lado, o espaço urbano também é visto como território político (ACSELRAD, 1999), no qual o lugar, entendido como espaço de uso coletivo, de habitação e de trânsitos, "torna-se o meio ambiente, gerando conflitos e tensões entre habitantes, lideranças políticas, a justiça e outros atores" (MOTA, 2007, sem paginação).

Oliveira (1998) ressalta a indissociabilidade do espaço urbano com as questões ambientais, a partir da concepção de que o espaço urbano e o meio natural são inseparáveis. Afinal, "o mundo material é entrecortado por sujeitos sociais que elaboram projetos distintos de uso e significação do espaço, seja ele rural ou urbano" (ZHOURI; PEREIRA, 2005, p. 16). Nesse contexto, o ambientalismo passou a ser tomado como exemplo paradigmático da perspectiva de ampliação do olhar histórico e político, principalmente pelo seu potencial de integrar saberes, além de permitir problematizações complexa e, transversais sobre a realidade social e política (CARVALHO, 2006).

Convém ressaltar que a literatura registra uma diversidade de conceitos e vertentes no campo do ambientalismo, dos mais radicais (ecossocialismo) aos mais moderados, que resultaram no chamado capitalismo verde ou ambientalismo liberal (WANNER, 2015). Destaca-se ainda o socioambientalismo, ao propor a superação das dicotomias existentes entre as questões sociais e ambientais, além de defender maior participação dos movimentos sociais na elaboração de políticas públicas ambientais (SANTILLI, 2005). Cada vertente possui a sua própria identidade, visto que cada uma delas constitui um campo particular de disputas, com sua natureza própria, seus interesses, suas lógicas e estratégias de ação (IRWIN, 2013). O reconhecimento de tal pluralidade é indispensável 
para evitar o equívoco do pressuposto de um pensamento ecológico único e monolítico (YEARLEY, 2014).

Essa discussão se relaciona com as várias dimensões da sustentabilidade, conforme a classificação de Ignacy Sachs (1993): sustentabilidade econômica, social, ecológica, espacial/geográfica e cultural. Segundo o autor, a sustentabilidade econômica ${ }^{2}$ é focada na eficiência da alocação e gestão de recursos extraídos da natureza, além de racionalidade nos investimentos. Tal concepção surge no âmbito do conceito de desenvolvimento sustentável, cuja matriz é o projeto desenvolvimentista liberal. Trata-se, portanto, nas palavras de Boaventura Sousa Santos (2010, p. 275), de um "processo de politização do espaço da produção". Atualmente, associa-se à dimensão econômica da sustentabilidade a incorporação de princípios éticos tanto na produção como no consumo de bens, serviços e mercadorias (PITELIS, 2013).

A sustentabilidade social prioriza políticas de desenvolvimento humano para promover justiça social e reduzir desigualdades. Tem como perspectiva a própria noção de continuidade da vida em sociedade (DEMPSEY, 2011). A sustentabilidade ecológica, por sua vez, tem como pilar a preservação das fontes de recursos energéticos e naturais, com base na premissa de que o uso econômico dos bens naturais deve considerar os ciclos temporais inerentes às especificidades de cada ecossistema, a fim de garantir o equilíbrio da biodiversidade.

Estudos recentes relacionam a dimensão ecológica da sustentabilidade a conceitos como resiliência e adaptabilidade. A resiliência ambiental refere-se à capacidade de regeneração dos biomas perante a ação antrópica e seus impactos negativos (SPINELLI et al., 2016). Scheffer et al. (2015) entendem resiliência como a capacidade dos ecossistemas, da fauna e da flora de obterem um relativo equilíbrio após situações ambientalmente desfavoráveis, como secas, enchentes, queimadas, geadas etc. A resiliência favorece a adaptabilidade e reduz a vulnerabilidade frente às mudanças ambientais, incluindo as mudanças climáticas (BRAGA; GRUBER, 2013). Resiliência ambiental e adaptabilidade também se aplicam à capacidade das comunidades tradicionais e das populações urbanas frente às mudanças ambientais, econômicas, sociais e culturais (SILVA, 2015).

A sustentabilidade espacial refere-se às políticas para a ocupação do solo, com "uma espacialização mais equilibrada" (SICHE, 2017, p. 140). O pressuposto é o de que a ocupação desordenada do solo afeta o equilíbrio dos biomas e ecossistemas. A dimensão geográfica ou espacial da sustentabilidade diz respeito ainda às "condições locais de existência e reprodução social”, colocando

\footnotetext{
Tal concepção surge no âmbito do conceito de desenvolvimento sustentável, cuja matriz é o projeto desenvolvimentista liberal (CARVALHO, 1991).
} 
em debate "as condições de qualidade de vida das comunidades, em que grupos se encontram em situações de segregação espacial e ou segregação ambiental" (SILVA; SOUZA; LEAL, 2012, p. 22).

A sustentabilidade cultural consiste no respeito às tradições, comunidades nativas e o patrimônio cultural, a fim de possibilitar harmonia e continuidade em relação aos padrões culturais vigentes (SICHE, 2017).

Essa perspectiva analítica reforça a relação entre sustentabilidade e governança ambiental, especialmente em contextos eleitorais, momentos em que os candidatos apresentam à sociedade suas propostas, por meio dos seus respectivos programas de governo (BARROS, 2015a, 2015b). Tal relação se acentua no atual contexto de globalização da governança ambiental e de desenvolvimento de propostas para a sustentabilidade urbana em nível local (LOSS; ZOLET; PIRES, 2015).

\section{ANÁLISE DOS DADOS}

Como se vê no Quadro 1, dos 11 candidatos, apenas três não tratam de temáticas ambientais nos programas de governo: Carmen Migueles (Partido Novo), Cyro Garcia (PSTU) e Thelma Bastos (PCO). Informações obtidas por meio das entrevistas anônimas ${ }^{3}$ dão conta de que os três candidatos optaram por não incluir temas ambientais em seus programas de governo, mas por motivos diferentes. No caso de Migueles, "trata-se de um partido que não reconhece na questão ambiental uma prioridade política para o País. Mesmo sendo uma legenda nova, suas prioridades são a reestruturação do Estado e o combate à corrupção" (informação verbal) ${ }^{4}$. No caso de Cyro Garcia e Thelma Bastos, os informantes argumentam que seus partidos elegeram outras prioridades e que a agenda ambiental nunca fez parte da pauta dos dois partidos.

O candidato Crivella mencionou o tema no programa, mas de forma avulsa, ou seja, sem destinar um capítulo específico ao tema no seu programa de governo. A justificativa, segundo o profissional entrevistado, que atuou na campanha eleitoral do candidato, é que "meio ambiente nunca foi um tema forte na trajetória política de Crivella, o que o levou a ter cautela com esse assunto, para não parecer oportunista perante o seu eleitorado" (informação verbal) 5 . Além disso, esse mesmo entrevistado complementa: "o candidato tem uma carreira

3 Os entrevistados concordaram em participar da pesquisa somente com a garantia de anonimato em razão de exercerem cargos de confiança na prestação de serviços aos candidatos.

4 Informação fornecida mediante entrevista por telefone. No dia 17 de novembro de 2017.

5 Informação fornecida por Informação fornecida mediante entrevista por telefone. No dia 18 de novembro de 2017. 
política sólida, uma imagem pública consolidada e um eleitorado fiel, cujas preocupações são outros temas, mais ligados a valores familiares e humanos e não tanto o meio ambiente".

Quadro 1 - Temáticas ambientais nos programas dos candidatos

\begin{tabular}{|l|l|l|c|c|l|c|c|}
\hline & Candidatos & \multicolumn{1}{|c|}{$\begin{array}{c}\text { Partido / } \\
\text { Coligação }\end{array}$} & \multicolumn{2}{c|}{$\begin{array}{c}\text { Ocorrência/ } \\
\text { Peso }\end{array}$} & \multicolumn{2}{|c|}{$\begin{array}{l}\text { Inserção no } \\
\text { Programa / Peso }\end{array}$} & $\begin{array}{c}\text { Índice } \\
\text { Geral }\end{array}$ \\
\hline 1 & $\begin{array}{l}\text { Alessandro } \\
\text { Molon }\end{array}$ & PV / REDE / PPL & Sim & 1,0 & Capítulo & 1,0 & 2,00 \\
\hline 2 & $\begin{array}{l}\text { Carmen } \\
\text { Migueles }\end{array}$ & Partido Novo & Não & 0 & Não & 0 & 0 \\
\hline 3 & Crivella & PRB / PTN / PR & Sim & 1,0 & Avulso & 0,5 & 1,5 \\
\hline 4 & Cyro Garcia & PSTU & Não & 0 & Sem menção & 0 & 0 \\
\hline 5 & $\begin{array}{l}\text { Flávio } \\
\text { Bolsonaro }\end{array}$ & $\begin{array}{l}\text { PSC / PRP } \\
6\end{array}$ & Sim & 1,0 & Capítulo & 1,0 & 2,0 \\
\hline 7 & Jandira Feghali & PC do B / PT & Sim & 1,0 & Capítulo & 1,0 & 2,0 \\
\hline 8 & Marcelo Freixo & PSOL / PCB & Sim & 1,0 & Capítulo & 1,0 & 2,0 \\
\hline 9 & Osorio & PSDB / PPS & Sim & 1,0 & Capítulo & 1,0 & 2,0 \\
\hline 10 & Pedro Paulo & $\begin{array}{l}\text { PMDB / PDT / } \\
\text { PP / PTB / PSL } \\
/ \text { SD / DEM / } \\
\text { PROS / PHS / } \\
\text { PMN / PEN / } \\
\text { PSDC / PTC / PT } \\
\text { do B / PRTB }\end{array}$ & 1,0 & Capítulo & 1,0 & 2,0 \\
\hline 11 & Thelma Bastos & PCO & Sim & 1,0 & Capítulo & 1,0 & 2,0 \\
\hline
\end{tabular}

Fonte: Elaboração do autor, com base em dados de pesquisa própria.

A competição eleitoral certamente é um das justificativas para a adesão dos candidatos à agenda verde (BARROS, 2015a, 2015b; DUVERGER, 2011; SAINTENY, 1994). Afinal, incluir propostas ambientais, mesmo que não seja uma prioridade do partido do candidato, torna-se uma estratégia e um diferencial para aumentar a visibilidade na arena eleitoral, talvez por um imperativo político contextual e pela própria concorrência partidária. A constatação de que um determinado candidato ou partido inclui propostas de governança ambiental, instiga os demais a fazerem o mesmo (BARROS, 2015a, 2015b).

$\overline{6}$ Nome registrado na Justiça Eleitoral. 
A competição conduz a padrões similares, com a ênfase a alguns focos que se repetem, como a própria ideia de sustentabilidade, com o objetivo de adotarem estratégias focadas em articular conexões com os mesmos públicos do mercado eleitoral (BARROS, 2015a). Trata-se, portanto, de uma escolha estratégica para responder a uma demanda contextual que adquiriu relevância inclusive do ponto de vista eleitoral, como mostram os estudos de Sainteny (1994) e Duverger (2011). A inclusão de temáticas ambientais no programa partidário pode ser interpretada, portanto, como estratégia para fortalecer a reputação pública das legendas e de seus candidatos. Além disso, essa iniciativa contribuiu para a transformação do ambientalismo em um eixo de reflexão e de ação política (IRAZÁBAL, 2017; ROHRSCHNEIDER; MILES 2015), especialmente com a politização do debate sobre mudanças climáticas (PEPERMANS; MAESEELE, 2016; RYAN, 2017) ${ }^{7}$. Nesse debate destacam-se, atualmente, dois focos: modelos de governança global das questões climáticas (FRANCHINI et al., 2017) e o desenvolvimento de tecnologias adequadas à nova realidade ambiental (JACOBI; GIATTI, 2017; LEFF, 2015, 2017).

A estratégia de incluir temáticas ambientais no programa partidário é visível quando analisamos os eixos temáticos dos programas dos candidatos e seus respectivos termos-chave, como mostra o Quadro $2^{8}$. É a partir de eixos temáticos relacionados ao espaço urbano que as dimensões da sustentabilidade e os termoschaves são definidos pelos programas dos candidatos. As várias dimensões da sustentabilidade foram consideradas a partir das tipologias mais relevantes registradas na literatura. Aqui nos utilizamos especificamente da contribuição de Sachs (1993), conforme foi abordado anteriormente. Nesse quesito há mais semelhanças do que diferenças, o que se justifica pela especificidade da temática e pela correlação entre os diferentes assuntos e as dimensões de sustentabilidade a eles associados. As semelhanças identificadas certamente se justificam pelos diagnósticos comuns em relação aos principais problemas ambientais da cidade.

A sustentabilidade ecológica está presente em todos os programas, bem como a sustentabilidade espacial. Quanto à dimensão econômica da sustentabilidade, apenas o programa de Flávio Bolsonaro não contempla em função da limitação temática da proposta, como se vê no Quadro 3. Os candidatos Jandira Feghali e Marcelo Freixo são os únicos que contemplam a

7 Nesse debate, a literatura recente destaca uma polarização partidária nos Estados Unidos. De um lado estão os Democratas, que defendem as políticas de combate ao aquecimento global e de outro os Republicanos, contrários a tais medidas (DUNLAP; MCCRIGTH; YAROSH, 2016).

8 Os termos-chave foram identificados com o auxílio do software Atlas.Ti, com base na lógica da análise categorial ou temática, uma das ferramentas da análise de conteúdo (BARDIN, 2009). Para cada programa de governo utilizado, o software contabilizou e listou os termos mais citados no texto. Foram incluídos como termos-chave aqueles com o maior número de menções. 
dimensão cultural da sustentabilidade em seus programas de governo, embora de forma tímida, pois se limitam a mencionar temas como a preservação da paisagem ambiental e cultural e turismo sustentável. Os entrevistados, por sua vez, destacam que são dois candidatos diretamente envolvidos com as políticas culturais, tanto em função do perfil político de cada um quanto da atuação dos partidos aos quais são vinculados.

Quadro 2 - Programas agrupados por eixos temáticos, sustentabilidade e termoschave $^{9}$

\begin{tabular}{|c|c|c|c|c|}
\hline & Candidatos & $\begin{array}{c}\text { Eixo } \\
\text { temático }\end{array}$ & $\begin{array}{l}\text { Sustentabilidade } \\
\text { correspondente }\end{array}$ & $\begin{array}{c}\text { Termos-chaves mais citados } \\
\text { nos programas }\end{array}$ \\
\hline 1 & $\begin{array}{l}\text { Alessandro } \\
\text { Molon }\end{array}$ & $\begin{array}{c}\text { Cidade sus- } \\
\text { tentável }\end{array}$ & $\begin{array}{l}\text { Sustentabilidade } \\
\text { econômica, social, } \\
\text { ecológica e espacial. }\end{array}$ & $\begin{array}{c}\text { Bacias hidrográficas, } \\
\text { despoluição de baías, qualidade } \\
\text { de vida urbana, recuperação de } \\
\text { rios, hortas urbanas, serviços } \\
\text { de saneamento, reciclagem. }\end{array}$ \\
\hline 2 & Crivella & Urbanismo & $\begin{array}{c}\text { Sustentabilidade } \\
\text { econômica, } \\
\text { ecológica e espacial. }\end{array}$ & $\begin{array}{c}\text { Mobilidade urbana; despoluição } \\
\text { de lagoas; despoluição de } \\
\text { canais. }\end{array}$ \\
\hline 3 & $\begin{array}{c}\text { Flávio } \\
\text { Bolsonaro }\end{array}$ & Urbanismo & $\begin{array}{c}\text { Sustentabilidade } \\
\text { ecológica e espacial. }\end{array}$ & $\begin{array}{c}\text { Arborização urbana; } \\
\text { esverdeamento da cidade; } \\
\text { resíduos sólidos. }\end{array}$ \\
\hline 4 & $\begin{array}{c}\text { Índio da } \\
\text { Costa }\end{array}$ & $\begin{array}{l}\text { Sustenta- } \\
\text { bilidade } \\
\text { urbana }\end{array}$ & $\begin{array}{l}\text { Sustentabilidade } \\
\text { econômica, } \\
\text { ecológica e espacial. }\end{array}$ & $\begin{array}{l}\text { Sustentabilidade; matas, } \\
\text { florestas, rios, lagoas, qualidade } \\
\text { de vida urbana; práticas } \\
\text { ambientais ecoeficientes. }\end{array}$ \\
\hline 5 & $\begin{array}{l}\text { Jandira } \\
\text { Feghali }\end{array}$ & $\begin{array}{l}\text { Sustenta- } \\
\text { bilidade } \\
\text { urbana }\end{array}$ & $\begin{array}{l}\text { Sustentabilidade } \\
\text { econômica, social, } \\
\text { ecológica, espacial e } \\
\text { cultural. }\end{array}$ & $\begin{array}{l}\text { Impactos ambientais; agenda } \\
\text { ambiental; licenciamento } \\
\text { ambiental; preservação; } \\
\text { unidades de conservação; } \\
\text { educação ambiental; } \\
\text { saneamento ambiental; } \\
\text { financiamento verde; resíduos } \\
\text { domiciliares; preservação do } \\
\text { patrimônio natural e cultural; } \\
\text { turismo sustentável. }\end{array}$ \\
\hline
\end{tabular}

9 Os eixos temáticos foram definidos com base em critérios similares aos termos-chave, com o auxílio do mesmo software. A diferença é que para ser considerado um eixo temático o critério adicional é que houve um tópico com a referida nomenclatura no texto do programa de cada candidato. O tipo de sustentabilidade correspondente foi definido com base na literatura, especialmente Sachs (1993). 


\begin{tabular}{|c|c|c|c|c|}
\hline 6 & $\begin{array}{c}\text { Marcelo } \\
\text { Freixo }\end{array}$ & $\begin{array}{l}\text { Justiça } \\
\text { socioam- } \\
\text { biental }\end{array}$ & $\begin{array}{c}\text { Sustentabilidade } \\
\text { econômica, social, } \\
\text { ecológica, espacial e } \\
\text { cultural. }\end{array}$ & $\begin{array}{l}\text { Saneamento ambiental; } \\
\text { planejamento e gestão } \\
\text { ambiental; política municipal } \\
\text { de mudanças climáticas; } \\
\text { zoneamento-ecológico- } \\
\text { econômico; unidades de } \\
\text { conservação; arborização } \\
\text { urbana; licenciamento } \\
\text { ambiental; ecoeficiêcia; } \\
\text { educação ambiental; recursos } \\
\text { hídricos; lixo orgânico; turismo } \\
\text { sustentável. }\end{array}$ \\
\hline 7 & Osorio & $\begin{array}{c}\text { Sustenta- } \\
\text { bilidade e } \\
\text { saneamento }\end{array}$ & $\begin{array}{l}\text { Sustentabilidade } \\
\text { econômica, } \\
\text { ecológica e espacial. }\end{array}$ & $\begin{array}{l}\text { Sustentabilidade; saneamento; } \\
\text { patrimônio ambiental; recursos } \\
\text { hídricos; alagamentos e } \\
\text { inundações; zoneamento } \\
\text { econômico-ecológico; } \\
\text { compensação ambiental; } \\
\text { reciclagem; arborização; } \\
\text { educação ambiental; defesa e } \\
\text { proteção dos animais. }\end{array}$ \\
\hline 8 & Pedro Paulo & $\begin{array}{l}\text { Cidade sus- } \\
\text { tentável }\end{array}$ & $\begin{array}{l}\text { Sustentabilidade } \\
\text { econômica, social, } \\
\text { ecológica e espacial. }\end{array}$ & $\begin{array}{c}\text { Desenvolvimento sustentável, } \\
\text { eficiência energética; } \\
\text { zoneamento econômico- } \\
\text { ecológico, planejamento } \\
\text { urbano, infraestrutura } \\
\text { verde, mudanças climáticas; } \\
\text { reciclagem, edifícios } \\
\text { ecoeficientes, alagamentos e } \\
\text { inundações, gestão de resíduos } \\
\text { sólidos. }\end{array}$ \\
\hline
\end{tabular}

Fonte: Elaboração do autor, com base nos programas dos candidatos.

Ao observarmos as propostas específicas para as políticas ambientais de cada um(a) dos(as) candidatos(as), como se lê no Quadro 3, destacam-se as propostas contidas no programa de Pedro Paulo, o único candidato cujas proposições, além de incluir as dimensões econômica, social, ecológica e espacial da sustentabilidade, são enunciadas na forma de metas, incluindo os percentuais almejados e o tempo para a consecução. Em segundo lugar, em termos de consistência e relevância, estão as propostas de Alessandro Molon, Jandira Feghali e Marcelo Freixo, por serem as únicas que contemplam todas as dimensões da sustentabilidade, inclusive a dimensão cultural, que é de grande relevância para uma cidade como o Rio de Janeiro. 
Na sequência têm-se as propostas do candidato Osório, que abrangem três dimensões da sustentabilidade e o detalhamento das medidas. Em último lugar estão as propostas dos candidatos Crivella, Flávio Bolsonaro e Índio da Costa, por serem as menos abrangentes e de menor consistência, limitadas as questões genéricas, como qualidade de vida urbana, despoluição de lagoas e urbanização de áreas degradadas.

Quadro 3 - Propostas dos candidatos para a gestão ambiental da cidade ${ }^{10}$

\begin{tabular}{|c|c|c|}
\hline & Candidatos & Propostas de políticas ambientais \\
\hline 1 & $\begin{array}{l}\text { Alessandro } \\
\text { Molon }\end{array}$ & $\begin{array}{l}\text { - Desenho urbano de matriz ecológica; } \\
\text { - Sustentabilidade como eixo transversal para a gestão da cidade; } \\
\text { - Revisão da política de reurbanização portuária; } \\
\text { - Recuperação dos rios urbanos; } \\
\text { - Urbanização de favelas; } \\
\text { - Uso de alimentos orgânicos na merenda escolar; } \\
\text { - Adoção de projetos de agricultura urbana; } \\
\text { - Universalização dos serviços de saneamento (água, esgoto e lixo); } \\
\text { - Coleta e tratamento sustentável dos resíduos sólidos; } \\
\text { - Participação social na política de mobilidade urbana; } \\
\text { - Estímulo à inovação e políticas criativas; } \\
\text { - Preservação da memória local. }\end{array}$ \\
\hline 2 & Crivella & $\begin{array}{l}\text { - Despoluição das lagoas e dos canais da Barra da Tijuca e de } \\
\text { Jacarepaguá em até } 8 \text { anos; } \\
\text { - Criação de um parque ecológico entre Bangu e Campo Grande } \\
\text { até o final de 2019; } \\
\text { - Ampliação das redes de coleta e tratamento de esgoto sanitário. }\end{array}$ \\
\hline 3 & $\begin{array}{l}\text { Flávio } \\
\text { Bolsonaro }\end{array}$ & $\begin{array}{l}\text { - Recuperação e ampliação de áreas verdes da cidade; } \\
\text { - Isenções tributárias para fomentar parcerias público-privadas } \\
\text { para a recuperação ambiental de parques, praças e jardins públicos; } \\
\text { - Ampliação das redes de coleta e tratamento de esgoto sanitário; } \\
\text { - Urbanização e regularização de áreas urbanas degradadas. }\end{array}$ \\
\hline 4 & $\begin{array}{l}\text { Índio da } \\
\text { Costa }\end{array}$ & $\begin{array}{l}\text { - Proteção de matas, rios e florestas urbanas; } \\
\text { - Transformação do Rio em uma cidade sustentável, com } \\
\text { qualidade de vida urbana. }\end{array}$ \\
\hline 5 & $\begin{array}{l}\text { Jandira } \\
\text { Feghali }\end{array}$ & $\begin{array}{l}\text { - Consolidação da política de planejamento ambiental; } \\
\text { - Implantação do Sistema Municipal de Habitação de Interesse } \\
\text { Social; } \\
\text { - Ampliação do estoque de terras públicas; } \\
\text { - Urbanização de favelas e assentamentos; } \\
\text { - Ampliação das ciclovias; } \\
\text { - Fortalecimento do Conselho Municipal de Meio Ambiente; } \\
\text { - Reforço dos projetos de educação ambiental; } \\
\text { - Revisão das regras do Fundo de Conservação Ambiental. }\end{array}$ \\
\hline
\end{tabular}

10 As propostas foram extraídas literalmente do texto dos programas dos candidatos. 


\begin{tabular}{|l|l|l|}
\hline \multirow{5}{*}{6} & $\begin{array}{l}\text { - Implantação do Plano Municipal de Justiça Socioambiental; } \\
\text { Freixo }\end{array}$ \\
- Implementação da Política Municipal de Mudanças Climáticas; \\
- Ampliação da rede de unidades de conservação do município; \\
- Combate às indústrias poluidoras e desmatadoras; \\
- Fortalecimento dos mecanismos de mapeamento e contenção de \\
riscos ambientais; \\
- Criação de uma empresa pública de saneamento ambiental; \\
- Instituição de um plano municipal de preservação da paisagem \\
ambiental; \\
- Criação de um sistema de informações para o combate aos \\
crimes contra animais.
\end{tabular}

Fonte: Elaboração do autor, com base em dados de pesquisa própria.

O conteúdo das entrevistas ajuda a compreender como as propostas foram formuladas e como se deu a negociação interna para a composição do elenco de proposições. Conforme os informantes os candidatos que se envolveram diretamente na formulação das proposituras para a área ambiental e fizeram questão de que o tema fosse central em seus programas foram Alessandro Molon, Jandira Feghali e Marcelo Freixo. Além do conhecimento pessoal dos candidatos sobre o tema, foram acionados especialistas em políticas ambientais para ajudarem na formulação das propostas de cada candidato. Outro fator relevante indicado pelos entrevistados é a relação dos três candidatos mencionados com as redes de movimentos sociais de orientação ecológica. Para os informantes esse tipo de envolvimento dos candidatos "empodera a agenda ambiental municipal, pois 
aproxima os candidatos dos movimentos e vice-versa e isso se traduz em trocas de informações, de conhecimentos e de experiências" (informação verbal) ${ }^{11}$.

No caso de Pedro Paulo, o informante relata que "a presença do $\mathrm{PEN}^{12}$ na coligação contribui muito para a feição final do capítulo sobre meio ambiente" (informação verbal) ${ }^{13}$. Além disso, acrescenta que "o PEN contribuiu com uma equipe especializada em no assunto", mas o próprio candidato exerceu protagonismo na construção do texto, pois "ele insistiu para que as propostas fossem viáveis, concretas e mensuráveis, incluindo metas e prazo", explica o entrevistado da equipe de marketing político do candidato. "Para o candidato isso era uma questão de honra, pois ele é contra propostas genéricas e vazias, que são usadas, na maioria das vezes, de forma demagógica no discurso político durante as campanhas eleitorais", complementa.

Em relação aos demais candidatos, após a análise das entrevistas, percebese que os programas são menos enfáticos e com propostas menos elaboradas, devido a três fatores: (a) o perfil dos candidatos, que são menos envolvidos com a agenda ambiental; (b) a falta de interlocução com os movimentos e entidades ambientalista; (c) falta de expertise das equipes de marketing político no assunto. Em suma, as entrevistas, na forma como foram realizadas, foram de grande utilidade para o aprofundamento qualitativo da análise, contextualizando os dados, como salientam Alves e Silva (1992).

\section{ANÁLISE DOS PROGRAMAS DOS CANDIDATOS}

Como já vimos acima, os programas mais abrangentes e que contemplam uma diversidade maior de dimensões da sustentabilidade são os de Alessandro Molon, Jandira Feghali, Marcelo Freixo e Pedro Paulo. Faremos agora um detalhamento do conteúdo dos programas desses três candidatos. Os três apresentam uma perspectiva sistêmica da sustentabilidade, ou seja, alberga as variadas dimensões da sustentabilidade, com a proposta de ações convergentes, integradas e coordenadas. Os ecologistas sistêmicos pregam transformações sociopolíticas e culturais amplas, associando democracia e cidadania ecológica. As pautas defendidas pelos programas partidários desse segmento são amplas, incluindo temas como cultura de paz, justiça social, direitos humanos, desenvolvimento regional e economia solidária (BARROS, 2015a).

\footnotetext{
Informação fornecida mediante entrevista por telefone. No dia 18 de novembro de 2017. Partido Ecológico Nacional (PEN).

13 Informação fornecida mediante entrevista por telefone. No dia 17 de novembro de 2017.
} 
No caso do programa de Molon, essa perspectiva aparece logo na abertura do texto que apresenta o programa de governo do candidato:

Propomos um novo tipo de desenvolvimento para o Rio, que seja sustentável e eficiente, tendo como pontos centrais o meio ambiente, a qualidade de vida dos cidadãos, a cultura e o conhecimento, com processos de decisão democratizados, participativos e transparentes, de forma a constituirmos uma cidade verdadeiramente inclusiva e integrada (REDE, 2016, p. 1).

No programa de Feghali, a visão defendida é a de que:

A agenda ambiental tem um intrínseco relacionamento com políticas públicas como: saúde, educação, mobilidade urbana, desenvolvimento econômico, dado o seu caráter abrangente; além, certamente, de sua área comum ao saneamento básico. Articuladamente ao planejamento para as políticas públicas em geral no município, a política pública ambiental deve andar em conjunto com as transformações da cidade (PCdoB, 2016, p. 31).

As propostas de Freixo têm como foco mudar o atual panorama ambiental da cidade do Rio, conforme destaca:

[...] apostando em um planejamento urbano que considere o papel do município do Rio na dinâmica socioambiental metropolitana. É necessário ter um plano integrado que respeite o meio ambiente, as culturas locais, a soberania alimentar e a matriz socioeconômica de cada região. Precisamos tornar o Rio mais saudável e ecológico (PSOL, 2016, p. 11).

No caso dos programas supracitados, os trechos reproduzidos literalmente reforçam nitidamente a perspectiva sistêmica já mencionada. Isso pode ser observado nas propostas de Molon por meio da articulação estabelecida entre governança ambiental, qualidade de vida, cultura, conhecimento, participação e inclusão social (REDE, 2016). Outro exemplo está na interrelação entre a governança ambiental e as demais políticas públicas, especialmente em áreas como saúde, educação, mobilidade urbana, saneamento básico e desenvolvimento econômico, conforme demonstram as propostas de Feghali (PCdoB, 2016). No programa de Freixo, por sua vez, notou-se a associação da dinâmica socioambiental metropolitana com questões relacionadas ao uso do território e suas características naturais, sociais, econômicas e culturais (PSOL, 2016).

As propostas de Pedro Paulo apresentam como diferencial, o estabelecimento de metas, como já foi abordado acima. As propostas são ancoradas no argumento geral de que:

O século XXI será inevitavelmente marcado pelo desafio do desenvolvimento sustentável. É o principal tema da agenda econômica, 
social e cultural das próximas décadas. Desse modo, o Rio, mesmo considerando todas as suas mazelas ambientais, fruto de um estoque criado por séculos de descaso e incompreensão do valor desse ativo intangível para o desenvolvimento e o bem-estar dos cariocas, é a expressão do desafio da humanidade nesse momento histórico (PMDB, 2016, p. 39).

O eixo argumentativo que ancora as propostas do candidato Osório é o desenvolvimento econômico:

O Rio precisa reorientar seu eixo de desenvolvimento econômico para as suas vocações e vantagens competitivas. Nosso objetivo é criar uma base sustentável para o desenvolvimento econômico, com impactos positivos em emprego e renda. Nossa estratégia gira em torno de dois pilares fundamentais: (1) Valorizar as atividades produtivas nas quais já desempenhamos um papel de excelência e em que estamos na liderança no Brasil; (2) Reforçar e desenvolver atividades que valorizem e se beneficiem da sua beleza natural e cultura local, que tornam a cidade única e criam um sentimento de bem estar difícil de replicar em qualquer outra cidade (PSDB, 2016, p. 12).

O programa de Crivella, no tópico avulso sobre meio ambiente, inserido no item "Outras Temáticas", limita-se a apresentar suas metas, as quais já foram descritas no Quadro 3, sem uma justificação argumentativa (PRB, 2016). O candidato Bolsonaro argumenta em seu programa de governo que o foco de sua gestão ambiental será “o esverdeamento da cidade, pois uma cidade verde é uma cidade mais bonita e mais feliz, e o processo de maturação urbana reduzirá sensivelmente as temperaturas no verão da cidade maravilhosa" (PSC, 2016, p. 5).

O programa de governo de Índio da Costa, no quesito ambiental, apresenta como principal objetivo "transformar o Rio de Janeiro em uma cidade sustentável, com práticas eficientes voltadas para a melhoria da qualidade de vida da população, desenvolvimento econômico e preservação do meio ambiente" (PSD, 2016, p. 23).

Comparando os programas dos candidatos, além das semelhanças já apontadas acima, observam-se ainda alguns padrões quanto à lógica dos programas e seus perfis. Existem programas que resultam do empenho pessoal dos candidatos, que atuam como empreendedores da gestão ambiental (Alessandro Molon, Jandira Feghali e Marcelo Freixo), bem como aqueles cujas propostas estão atreladas à identidade partidária (Alessandro Molon, da Coligação PV e Rede-RJ). Por fim, está Crivella, candidato do tipo free-rider, que "pegou carona" na onda verde.

Enquanto o texto dos programas de Molon, Feghali e Freixo demonstram mais familiaridade dos candidatos com os temas ambientais, os demais soam 
como ambientalistas acidentais (BARROS, 2018), ou seja, incluíram temas verdes em seus programas de governo por mera conveniência eleitoral, em função da relevância do tema para a cidade do Rio de Janeiro e para o eleitorado. Os programas de Molon, Feghali e Freixo tratam as questões ambientais de forma sistêmica, isto é, relacionam suas propostas ambientais de forma integrada com as várias dimensões da sustentabilidade. No caso de Molon, o texto trata a sustentabilidade como "eixo transversal para a gestão da cidade", além de propor a participação democrática nos processos decisórios relacionados à mobilidade urbana. O programa de Feghali segue a mesma tendência, ao propor políticas de planejamento ambiental integrado com mobilidade urbana (ciclovias), educação ambiental e participação da sociedade, via Conselho Municipal de Meio Ambiente. O programa de Freixo, por sua vez, relaciona a governança ambiental da cidade com justiça ambiental, prevenção de riscos ambientais e a adoção de um plano municipal de preservação da paisagem ambiental.

\section{CONCLUSÕES}

$\mathrm{O}$ artigo teve como objetivo analisar como os candidatos à prefeitura da cidade do Rio de Janeiro em 2016 abordaram os temas da agenda ambiental no âmbito local. Uma breve sistematização das principais conclusões extraídas da discussão teórica mostra que a governança ambiental é indispensável para a garantia da qualidade de vida urbana, considerando as várias dimensões da sustentabilidade (CÂMARA, 2013; DEMPSEY, 2011;DUNLAP; BRULLE, 2015; PITELIS, 2013; SACHS, 1993). No âmbito da governança ambiental, a gestão urbana ecoeficiente deve ser orientada por políticas públicas ambientalmente dirigidas para a mitigação e a prevenção de impactos e riscos ambientais (BROTO, 2017; CHAFFIN et al., 2016; IRAZÁBAL, 2017; SICHE, 2017).

Ao se cotejar os dados com a referida sistematização teórica, observa-se que a apresentação de propostas de governança ambiental pelos candidatos foi algo expressivo. Tanto é que dos 11 candidatos, 8 propuseram medidas de gestão do meio ambiente contemplando diversas visões de sustentabilidade. Em relação ao conteúdo das proposições, a análise revela três perfis de programas ${ }^{14}$. O primeiro é formado pelos candidatos Alessandro Molon, Jandira Feghali, Marcelo Freixo e Pedro Paulo. São documentos mais abrangentes e com maior nível de elaboração técnica. Com base nas entrevistas foi possível identificar as razões que

\footnotetext{
14 Os critérios para enquadramento do programa dos candidatos nos três perfis mencionados foram: a análise de conteúdo do texto e os depoimentos coletados por meio das entrevistas. Para tanto, levou-se em conta: a consistência, abrangência e nível de elaboração das propostas de governança ambiental.
} 
explicam esse primeiro perfil: o empenho pessoal dos candidatos, em função do envolvimento deles com o tema em suas trajetórias na política; a proximidade deles com os movimentos sociais de orientação ecológica; e a colaboração de especialistas em políticas ambientais na formulação das proposituras.

O segundo perfil é composto pelos candidatos Crivella, Flávio Bolsonaro, Índio da Costa e Osório. São programas de menor abrangência e com menos sofisticação técnica na elaboração das propostas, se comparados com os textos do grupo um. Da mesma forma, as entrevistas nos permitem avaliar que isso se deu pelos seguintes fatores: (a) falta de empenho pessoal dos candidatos, por não se tratar de prioridade eleitoral na visão deles; (b) ausência de vínculos diretos dos candidatos com os movimentos/entidades ambientais; (c) falta de colaboração de especialistas em políticas ambientais; (d) constatação dos próprios candidatos de que a ênfase no tema não produziria impacto em suas bases eleitorais, cujos focos temáticos são outros.

O terceiro perfil inclui aqueles que não trataram de temas ambientais, demonstrando que o assunto não tinha prioridade em suas propostas de governança urbana. São eles: Carmen Migueles (Partido Novo), Cyro Garcia (PSTU) e Thelma Bastos (PCO).

Retomando as questões que orientam o estudo, especialmente a primeira (como se deu a incorporação de temas ambientais no programa dos candidatos?), percebe-se que a inserção de tópicos ambientais no programa dos candidatos ocorreu de forma diferenciada, em consonância com os três perfis acima descritos. Como já foi mencionado, os candidatos que dedicaram maior importância à agenda verde apresentam um conjunto de fatores que contribuíram para isso: o engajamento pessoal dos candidatos, que atuaram como empreendedores ambientais; a abertura para as ideias dos movimentos ecológicos e de experts. Aqueles que, ao contrário, não apresentam esse perfil, não priorizaram as temáticas ambientais em seus respectivos programas de governo.

A conjunção dos fatores acima mencionados contribui para explicar a segunda questão: como as temáticas ambientais foram incorporadas nos programas dos candidatos? A trajetória pregressa dos candidatos e a aposta deles na visão de que se tratava de um tema relevante sob a ótica eleitoral favoreceu a inclusão de temas ambientais nas propostas de forma mais sistemática e orgânica, incluindo medidas relacionadas a aspectos de grande visibilidade na agenda de debates sobre as problemáticas atinentes à governança ambiental da cidade. Entre elas estão: sustentabilidade como eixo transversal para a gestão da cidade (no caso de Molon); consolidação da política de planejamento ambiental (Feghali); 
ampliação da rede de unidades de conservação do município (Freixo); redução em 35\% no volume de resíduos enviados para os aterros sanitários (Pedro Paulo).

Ao se discutir a terceira questão (em que consistem as propostas políticas apresentadas?), observa-se que o teor de tais proposições está diretamente associado aos três perfis de programas acima mencionados. Assim, no caso do primeiro perfil as medidas consistem em sugestões de ações convergentes, integradas e coordenadas. Entre elas destacam-se medidas para a promoção da cultura de paz, da justiça social, dos direitos humanos, do desenvolvimento regional e da economia solidária. Os candidatos dos demais perfis apresentam propostas menos consistentes e pouco articuladas, como já foi demonstrado acima.

Na sequência, convém ressaltar os dados relativos à última questão: qual(is) a(s) noção(ões) de sustentabilidade que orienta(m) o discurso dos candidatos? No caso do grupo que se enquadra no primeiro perfil, as ideias são ancoradas em uma visão sistêmica da sustentabilidade, de forma a articular suas várias dimensões. Nessa perspectiva, os candidatos sugerem amplas transformações na política e na cultura, de modo a incorporar ao debate sobre democracia a noção de cidadania ecológica. No caso dos demais perfis, ao contrário, faltam consistência e essa visão sistêmica nas propostas, conforme já foi abordado.

Por fim, cabe frisar que a análise documental, complementada pelas entrevistas, confirma a hipótese enunciada na introdução. A formulação de propostas de governança ambiental pelos candidatos mostrou-se uma estratégia relevante no contexto eleitoral. Conforme já registrado na literatura, trata-se de uma tática dos candidatos para se destacarem na arena eleitoral, quando vários temas entram em disputa pela atenção do eleitorado (BARROS, 2015a, 2015b; DUVERGER, 2011; SAINTENY, 1994). A inclusão de temáticas ambientais no programa partidário pode ser interpretada, portanto, como esforço para fortalecer a reputação pública das legendas e de seus candidatos. No caso em estudo, convém considerar ainda o peso das questões ambientais no debate político e na agenda midiática.

\section{REFERÊNCIAS}

ACSELRAD, H. Discursos da sustentabilidade urbana. Revista Brasileira de Estudos Urbanos e Regionais, Presidente Prudente, n. 1, p. 79-90, 1999.

ALVES, Z. M. M. B.; SILVA, M. H. G. F. Análise qualitativa de dados de entrevista: uma proposta. Paidéia, Ribeirão Preto, v. 2, n. 2, p. 61-69, 1992.

BARDIN, L. Análise de conteúdo. Lisboa: Edições 70, 2009. 
BARROS, A. T. Política partidária e meio ambiente: a adesão dos partidos políticos brasileiros à agenda verde. Opinião Pública, Campinas, v. 21, n. 3, p. 693-733, 2015a. Disponível em: http://www.scielo.br/pdf/op/v21n3/18070191-op-21-3-0693.pdf. Acesso em: 25 jan. 2018.

BARROS, A. T. Agenda verde internacional e seus impactos no Brasil. Revista de Estudos e Pesquisas Sobre as Américas, Brasília, v. 9, p. 160-191, 2015b.

BARROS, A. T. The internet as environmental media: strategies of Brazilian political parties. Ambiente \& Sociedade, São Paulo, v. 20, n. 1, p. 183-202, 2017a.

BARROS, A. T. Brazil's Discourse on the environment in the international arena. Contexto Internacional, Rio de Janeiro, v. 39, n. 2, p. 421-442, 2017 b.

BARROS, A. T. Ambientalistas acidentais: a adesão dos partidos políticos brasileiros ao liberalismo verde. Colombia Internacional, Bogotá, v. 15, n. 94, p. 111-141, 2018.

BRAGA, R. B.; GRUBER, N. L. S. Gestão do risco e adaptabilidade às mudanças ambientais dos municípios na planície costeira do Rio Grande do Sul. Gravel, Porto Alegre, v. 11, n. 1, p. 49-53, 2013.

BROTO, V. C. Urban governance and the politics of climate change. World Development, [S. l.], v. 93, n. 279, p. 1-15, 2017.

CÂMARA, J. B. D. Governança ambiental no Brasil. Revista de Sociologia e Política, Curitiba, v. 21, n. 46, p. 125-146, 2013.

CARVALHO, I. C. M. A eco-democracia. Revista Políticas Governamentais, São Paulo, v. 7, n. 75, p. 01, 1991.

CARVALHO, I. C. M. As transformações na esfera pública e a ação ecológica: educação e política em tempos de crise da modernidade. Revista Brasileira de Educação, São Paulo, v. 11, n. 32, p. 308-315, 2006.

CHAFFIN, B. C. et al. Transformative environmental governance.

Annual Review of Environment and Resources, New York, v. 41, n. 123, p. 399-423, 2016.

DEMPSEY, N. et al. The social dimension of sustainable development: defining urban social sustainability. Sustainable development, [S. l.], v. 19, n. 5, p. 289-300, 2011. 
DUNLAP, R. E.; BRULLE, R. J. Climate change and society: sociological perspectives. New York: Oxford University Press, 2015.

DUNLAP, R.; MCCRIGHT, A.; YAROSH, H. J. The political divide on climate change: Partisan polarization widens in the U.S. Environment: science and policy for sustainable development, [S. l.], v. 58, n. 5, p. 4-23, 2016.

DUVERGER, T. Le parti socialiste et l'écologie. Paris: Jean Jaurés Fondation, 2011.

FRANCHINI, M. et al. The challenges of the anthropocene: from international environmental politics to global governance. Ambiente \& Sociedade, São Paulo, v. 20, n. 3, p. 177-202, 2017.

IRAZÁBAL, C. City making and urban governance in the Americas: Curitiba and Portland. London: Routledge, 2017.

IRWIN, A. Sociology and the environment: a critical introduction to society, nature and knowledge. Cambridge: John Wiley \& Sons, 2013.

JACOBI, P.; GIATTTI, L. L. Nexos para a sustentabilidade: a busca por uma nova racionalidade. Ambiente \& Sociedade, São Paulo, v. 20, n .2, p. 12-24, 2017.

KLÜBER, T. E. Atlas/ti como instrumento de análise em pesquisa qualitativa de abordagem fenomenológica. Educação Temática Digital, Campinas, v. 16, n. 1, p. 5-23, 2014.

LEFF, H. Political ecology: a Latin American perspective. Revista

Desenvolvimento e Meio Ambiente, Curitiba, n. 35, p. 29-64, 2015.

LEFF, H. Power-knowledge relations in the field of political ecology. Ambiente \& Sociedade, São Paulo, v. 20, n. 3, p. 225-256, 2017.

LOSS, M. M. M.; ZOLET, L. A.; PIRES, C. Globalização, democracia e sustentabilidade: como resolver a equação? Revista Jurídica Cesumar, Maringá, v. 15, n. 1, p. 129-152, 2015.

LYNCH, K. A cidade como meio ambiente. In: DAVIS, K. et al. Cidades: a urbanização da humanidade. Rio de Janeiro: Zahar, 1972. p. 207-216.

MARQUES, E. C. Estado e redes sociais: permeabilidade e coesão nas políticas urbanas no Rio de Janeiro: Editora Revan, 2000.

MARQUES, E. C. L. A metrópole de São Paulo no início do século XXI.

Revista USP, São Paulo, n. 102, p. 23-32, 2014. 
MOTA, F. Quando a cidade vira meio ambiente: notas antropológicas sobre conflitos ambientais no Brasil. In: INTERNATIONAL CONFERENCE OF YOUNG URBAN RESEARCHERS, 1., 2007, Lisboa. Proceedings [...]. Lisboa: CYUR, p. 1-12. 2007.

NOVO. Novo. Novo, Rio de Janeiro, 2016. Disponível em: http:/ / divulgacandcontas.tse.jus.br/dados/2016/RJ/60011/2/190000011364/ proposta_governo1470932607699.pdf. Acesso em: 30 ago. 2016.

OLIVEIRA, J. P. Cidade e meio ambiente sob um enfoque sistêmico. TurismoVisão e Ação, Balneário Camboriú, v. 1, n. 1, p. 45-60, 1998.

PCdoB. Rio em comum. PCdoB, Rio de Janeiro, 2016. Disponível em: http:/ / divulgacandcontas.tse.jus.br/dados/2016/RJ/60011/2/190000011736/ proposta_governo1470938710461.pdf. Acesso em: 30 ago. 2016.

PCO. PCO. PCO, Rio de Janeiro, 2016. Disponível em: http:/ / divulgacandcontas.tse.jus.br/dados/2016/RJ/60011/2/190000024265/ proposta_governo1471293135592.pdf. Acesso em: 30 ago. 2016.

PEPERMANS, Y.; MAESEELE, P. The politicization of climate change: problem or solution? Wires Climate Change, [S. l.], v. 7, n. 4, p. 478-485, 2016. PITELIS, C. N. Towards a more 'ethically correct'governance for economic sustainability. Journal of Business Ethics, [S. l.], v. 118, n. 3, p. 655-665, 2013. PMDB. Juntos pelo Rio. PMDB, Rio de Janeiro, 2016. Disponível em: http:/ / divulgacandcontas.tse.jus.br/dados/2016/RJ/60011/2/190000011364/ proposta_governo1470932607699.pdf. Acesso em: 30 ago. 2016.

PRB. Por um Rio mais humano. PRB, Rio de Janeiro, 2016. Disponível em: http://divulgacandcontas.tse.jus.br/dados/2016/RJ/60011/2/190000017952/ proposta_governo1471038889100.PDF. Acesso em: 30 ago. 2016.

PSC. O Rio precisa de força para mudar. PSC, Rio de Janeiro, 2016. Disponível em: http://divulgacandcontas.tse.jus.br/dados/2016/ RJ/60011/2/190000011736/proposta_governo1470938710461.pdf. Acesso em: 30 ago. 2016.

PSD. Juntos pelo carioca. PSD, Rio de Janeiro, 2016. Disponível em: http:/ / divulgacandcontas.tse.jus.br/dados/2016/RJ/60011/2/190000011736/ proposta_governo1470938710461.pdf. Acesso em: 30 ago. 2016. 
PSDB. Rio de oportunidades e direitos. PSDB, Rio de Janeiro, 2016. Disponível em: http://divulgacandcontas.tse.jus.br/dados/2016/ RJ/60011/2/190000011364/proposta_governo1470932607699.pdf. Acesso em: 30 ago. 2016.

PSOL. Mudar é possível. PSOL, Rio de Janeiro, 2016. Disponível em: http:/ / divulgacandcontas.tse.jus.br/dados/2016/RJ/60011/2/190000007450/ proposta_governo1470756689345.pdf. Acesso em: 30 ago. 2016.

PSTU. Contra burguês, lute e vote 16. PSTU, Rio de Janeiro, 2016.

Disponível em: http://divulgacandcontas.tse.jus.br/dados/2016/ RJ/60011/2/190000019572/proposta_governo1471117955205.pdf. Acesso em: 30 ago. 2016.

REDE. Todo Rio. Rede, Rio de Janeiro, 2016. Disponível em: http:/ / divulgacandcontas.tse.jus.br/dados/2016/RJ/60011/2/190000018866/ proposta_governo1471112330764.pdf. Acesso em: 30 ago. 2016.

ROHRSCHNEIDER, R.; MILES, M. Representation through parties? Environmental attitudes and party stances in Europe in 2013. Environmental Politics, [S. l.], v. 24, n. 4, p. 617-640, 2015.

RYAN, D. Politics and climate change: exploring the relationship between political parties and climate issues in Latin America. Ambiente \& Sociedade, São Paulo, v. 20, n. 3, p. 271-286, 2017.

SACHS, I. Estratégias de transição para o século XXI. São Paulo: Nobel, 1993.

SAINTENY, G. Le Parti socialiste face à l'écologisme. Revue Française de Science Politique, Paris, v. 44, n. 3, p. 424-461, 1994.

SANTILLI, J. Socioambientalismo e novos direitos: proteção jurídica à diversidade biológica e cultural. São Paulo: Editora Peirópolis, 2005.

SANTOS, B. S. Pela mão de Alice. 6. ed. São Paulo: Cortez, 2010.

SCHEFFER, M. et al. Generic indicators of ecological resilience: inferring the chance of a critical transition. Annual Review of Ecology, Evolution, and Systematics, [S. l.], v. 46, n. 46, p. 145-167, 2015.

SICHE, R. et al. Índices versus indicadores: precisões conceituais na discussão da sustentabilidade de países. Ambiente \& sociedade, São Paulo, v. 10, n. 2, p. 137-148, 2017. 
SILVA, R. J. Repensando a premissa de adaptabilidade em comunidades tradicionais rurais: sistemas agroalimentares em transição? South American Journal of Basic Education, Technical and Technological, [S. l.], v. 2, n. 1, p. $40-55,2015$.

SILVA, A. S.; DE SOUZA, J. G.; LEAL, A. C. A sustentabilidade e suas dimensões como fundamento da qualidade de vida. Geografia em Atos, Presidente Prudente, v. 1, n. 12, p. 22-42, 2012.

SPINELLI, M. V. P. et al. Estudo sustentável da capacidade de carga antrópica e a sua influência no ponto de equilíbrio da resiliência ambiental. Revista Brasileira de Geografia Física, Recife, v. 9, n. 1, p. 185-199, 2016.

WANNER, T. The new 'passive revolution' of the green economy and growth discourse: maintaining the 'sustainable development' of neoliberal capitalism.

New Political Economy, [S. l.], v. 20, n. 1, p. 21-41, 2015.

YEARLEY, S. The green case (routledge revivals): a sociology of environmental issues, arguments and politics. London: Routledge, 2014. ZHOURI, A. K. L.; PEREIRA, D. Conflitos sociais e meio ambiente urbano. In: ZHOURI, A. K. L.; BARROS, D. P. (org.). A insustentável leveza da política ambiental: desenvolvimento e conflitos socioambientais. Belo Horizonte: Autêntica Editora, 2005. v. 1. p. 11-24. 
Novos Cadernos NAEA • v. 24 n. 1 • p. 123-145 • jan-abr 2021 